\title{
The role of TMPRSS2-Inhibitor Camostat in the pathogenesis of COVID-19 in lung cells“
}

\author{
Stefan Bittmann*, Elena Moschüring Alieva, Anne Weissenstein, Elisabeth Luchter, Gloria \\ Villalon \\ Department of Pediatrics, Ped Mind Institute (PMI), Germany \\ *Corresponding author: Stefan Bittmann MD, MA, Head of the Department of Pediatrics and Ped Mind Institute (PMI), Pedi \\ cian, Hindenburgring 4, D-48599 Gronau, Germany
}

\begin{tabular}{|c|c|}
\hline ARTICLE INFO & Abstract \\
\hline Received: 慧 April 14, 2020 & Citation: Stefan B, Elena Moschüring A, Anne We, Elisabeth L, Gloria V. The role of \\
\hline Published: 絊 May 08, 2020 & $\begin{array}{l}\text { TMPRSS2-Inhibitor Camostat in the pathogenesis of COVID-19 in lung cells". Biomed J } \\
\text { Sci \& Tech Res 27(3)-2020. BJSTR. MS.ID.004519. }\end{array}$ \\
\hline
\end{tabular}

\section{Editorial}

The enzymes trypsine, furine and other pro-protein convertases, cathepsin, transmembrane proteases (TMPRSS) and elastases play by the cell entry of Coronaviren (Coronaviridae) a role [1]. The protease TMPRSS2 and TMPRSS11a which exist in the respiratory tract richly and become on cell surfaces exprimed, promote the entry of the SARS-CoV-1-Virus. For the TMPRSS-Protease TMPRSS11d also as protease similar to trypsin of the human respiratory tract famously - a proteolytic activation of the spike protein was proved by SARS-CoV 1. TMPRSS2 carries out a complicated reaction with the ACE2 receptor once more what allows an efficient reaction penetration of the virus directly in the cell surface [2,3]. TMPRSS2 and TMPRSS11D activate the Spike protein, while they split it in the S1 and S2 subunits by which an endosomal independence cell entry into the cell membrane is allowed $[2,3]$. Camostat (mesylate) is supplied as a crystalline solid. A solution with proportions can be prepared by dissolving camostat (mesylate). In the solvent of choice, which should be cleaned with an inert gasoline.

Camostat (mesylate) is soluble in organic solvents like DMSO and dimethylformamide. The solubility of camostat (mesylate) in these solvents is about $25 \mathrm{mg} / \mathrm{ml}$. Camostat is an inhibitor of [2,4] -progate. It inhibits trypsin $(\mathrm{Ki}=1 \mathrm{~nm})$ and is anti-inflammatory, including plasmin, kallikrein and thrombin per person. Camostat holds the integration of the severe acute respiratory distress syndrome (SARS-CoV) and the glycoprotein SARS CoV 2 into

pseudotyped particles bubble-like Vero cells, Calu 3 cells and especially from human lung epithelium-wide cells when given at a concentration of $10 \mu \mathrm{M}$ [5]. It reduces the number of the genomewidth equivalents of SARS CoV 2. camostat inhibits the function of the sodium channel in human epithelial-wide cells of airways (IC 50 $=50 \mathrm{~nm}$ ) [2]. The management of camostat $(1 \mathrm{mg} / \mathrm{kg})$ inhibits the production of TNF- $\alpha$ and the monocyte chemoattractant protein 1 by monocytes and the proliferation of pancreatic star cells in the model of a rat with chronic pancreatitis [4]. The chemical name is Dimethylcarbamoylmethyl 4-(4-guanidinobenzoyloxy) phenyl acetate mono methane sulfonate.

The molecular formula is $\mathrm{C} 2 \mathrm{OH} 22 \mathrm{~N} 405-\mathrm{CH} 403 \mathrm{~S}$. Camostat has a molecular weight of 494.52. Camostat mesilate occurs as white crystals or a crystalline powder. It is soluble in water, slightly soluble in ethanol and insoluble in diethyl ether. The melting point is 194-198 degrees. Camostat as FOIPAN (R.O.K) is an oral protease inhibitor and will be produced as $100 \mathrm{mg}$ tablets. Camostat will be stored at room temperature, expiration date is 3 years after production. The typical dosage for oral use is $600 \mathrm{mg}$ of camostat mesilate daily in three doses. The dosage should be adjusted according the symptoms of the patient. Camostat will be produced by Ono Pharmaceuticals (Osaka, Japan). Foipan Tablets have identification code $0 \mathrm{NO} 305$, are $6.6 \mathrm{~mm}$ in diameter and have weight of $126 \mathrm{~g}$. The dosage form are film-coated tablets. Inactive 
ingredients include hydroxypropyl cellulose, carmellose calcium, magnesium stearate, polypropylene and lactose hydrate. Clinical adverse reactions were described as anaphylactoid symptoms, thrombocytopenia, hepatic function disorder and hyperkalemia.

Therefore, it is necessary to proof these parameter closely. Large doses of Foipan should not be used in pregnant women or in women who may possibly be pregnant. In animal studies, in rats, administration of Camostad at dosages not less than 40 times the human therapeutic dose $(400 \mathrm{mg} / \mathrm{kg} /$ day) resulted in fetal weight gain [6]. No clinical experience was made with low birth weight infants, neonates, infants or children. Concerning pharmacokinetics in healthy individuals, when a single dose of camostat mesilate of $200 \mathrm{mg}$ was administered to 5 healthy adults in fasted state, the plasma concentration of its active metabolite 4-(4-guanidinobenzoyloxy) phenyl acetate, a result of $87.1 \mathrm{ng} /$ ml 40 minutes after administration was found (Tmax(min) 40, Cmax (ng/ml) 87.1+-29.5, AUC (ngb min/ml) $10400+-1400$, T1/2 (min) 100+/-). Relating to further metabolism, carboxylate ester moiety of camostat mesilate is hydrolyzed to an active metabolite 4-(4-guanidinobenzoyloxy) phenyl acetate, which is further hydrolyzed to 4-guanidinobenzoic acid [7].

Camostat mesilate is hydrolyzed itself by carboxyesterase and aryl esterase (in vitro) [8]. Camostat did not inhibit CYP1A2, CYP2C9, CYP2C19, CYP2D6 and CYP3A4 $[9,10]$. It has been analyzed, that camostat mesilate after oral administration acts on kinin formation, fibrinolytic effects, coagulopathy and complementary system to immediately inhibit enzyme activities and their abnormal increases. In conclusion, TMPRSS2 plays an important role in the viral spread of MERS-CoV-2 and SARS-CoV within the respiratory tract of mouse models and in murine immunopathology [2,3]. A study conducted by Markus Hoffmann and Hannah Kleine-Weber of the German Primate Center together with other researchers, confirms that the SARS-CoV-2 virus also requires the presence of the ACE2 receptor and the TMPRSS2 enzyme in the cell membrane of lung cells, which cleaves the $S$ protein on the virus envelope in order to be able to enter the lung cell $[2,3]$. According to this study, the known inhibitor of TMPRSS2, camostat, significantly reduces the probability of penetration of SARS-CoV-2 in cell experiments in vitro and could be suitable for treatment [4]

According to studies, SARS-CoV-2, the virus responsible for COVID-19, needs the TMPRSS2 present in the human body to enter the host cell, which could be a starting point for treatment. The efficacy of the drug in cell cultures has already been demonstrated [2-4]. Therapeutic efficacy in COVID-19 patients still has to be tested in clinical trials. Likewise, the Primate Centre Göttingen will investigate whether the active substance can be injected directly into the lung. There are doubts whether camostat per se is sufficiently available in the lung. Foipan (camostat) is one of the drugs for which the German Federal Ministry of Health initiated centralized procurement in April 2020 for the treatment of infected and seriously ill COVID-19 patients in Germany. Since a COVID-19 therapy is an individual healing trial without clinical proof of efficacy, its use should be considered primarily for severe forms of COVID-19 on an individual (off-label) patient basis. The study of Hoffmann et al., published in CELL in april 2020, showed that SARS-CoV-2 uses TMPRRS2 for priming of spike protein and camostat mesylate, an inhibitor of TMPRSS2, blocks SARS-CoV-2 in lung cells in vitro [2]. Further immediate studies in human must follow now urgently.

\section{References}

1. Fiji S, Hitomi Y (1981) New synthetic inhibitors of C1r, C1 esterase, thrombin, plasmin, kallikrein and trypsin. Biochimica et Biophysica Acta (BBA)-Enzymology, Band 661: S342-345.

2. Hoffmann M, Kleine Weber H, Schroeder S, Nadine Krüger, Tanja Herrler, et al. (2020) SARS-CoV-2 cell entry depends on ACE2 and TMPRSS2 and is blocked by clinically proven protease inhibitor. Cell 181: 1-10.

3. Reinke LM (2016) Identifikation und funktionelle Charakterisierung von TMPRSS2-Spaltstellen im Spike-Protein des SARS-Coronavirus. Dissertation, Medizinische Fakultät der Georg-August Universität zu Göttingen.

4. Coote K, Atherton Watson HC, Sugar R (2009) Camostat attenuates airway epithelial sodium channel function in vivo through the inhibition of a channel-activating protease. J Pharmacol Exp Ther 329(2): 764-774.

5. Gibo J, Ito T, Kawabe K, Hisano T, Inoue M, et al. (2005) Camostat mesilate attenuates pancreatic fibrosis via inhibition of monocytes and pancreatic stellate cells activity. Lab Invest 85(1): 75-89.

6. Ishikawa Y (1980) Gendai Iryo 12(Extra Issue): 127.

7. Ohki S (1980) Gendai Iryo 12(Extra Issue): 71.

8. Nemoto $\mathrm{H}$ The enzymes involved in the metabolism of camostat mesilate. Internal data of Pharmaceutical Co., Ltd.

9. Matsunaga $\mathrm{N}$ The effect of camostat mesilate on CYP 450 isoenzymes. Internal data of Ono Pharmaceutical Co., Ltd.

10.(2020) Product Information FOIPAN Tablets $100 \mathrm{mg}$, Ono Pharmaceutical. Stand August 2009. 
ISSN: 2574-1241

DOI: $10.26717 /$ BJSTR.2020.27.004519

Stefan Bittmann. Biomed J Sci \& Tech Res

(c) (P) This work is licensed under Creative Commons Attribution 4.0 License

Submission Link: https://biomedres.us/submit-manuscript.php

$\begin{array}{ll}\text { BIOMEDICAL } & \text { Assets of Publishing with us } \\ \text { RESEARCHES } & \text { - Global archiving of articles } \\ \text { - Immediate, unrestricted online access }\end{array}$

